\title{
BASICS OF EVALUATION OF THERMAL RADIATION EFFECTS ON HUMANS IN INDUSTRIAL FIRES
}

\author{
Jakub DLABKA ${ }^{1}$, Barbora BAUDIŠOVÁ², Jakub ŘEHÁČEK ${ }^{3}$
}

Review article

\begin{tabular}{ll}
\hline Abstract: & The issues in evaluating the effects of industrial fires on humans are very complex. One \\
& of the major factors posing a danger to humans in a fire is heat flux. There are multiple \\
& ways to evaluate these effects and each has its own specifics and drawbacks. The aim \\
of this contribution is to analyze the basic parameters for various types of industrial \\
fires, radiative heat transfer characteristics and the way the heat flux transferred by \\
radiation affects human organism. Further discussed are basic means (models) to describe \\
relationship of heat flux and its effects on exposed individuals. \\
Probit function, analysis and evaluation of risks, model, heat flux, exposure time.
\end{tabular}

\section{Introduction}

For the elaboration of the " Risk analysis and its evaluation " document (hereinafter referred to as "RAE"), which is a compulsory component of the emergency documentation, according to the the Major Accident Prevention (hereinafter referred to as "MAP") Act No. 59/2006 Coll., the effects of fires in industrial plants on human lives and health must be evaluated.

Several types of models are used for determining these effects. A model is a simplified representation of reality; in this case, the models are simplified representations of the relationship between heat flux and its effects on humans. Most of the models described below are represented by a defined mathematical function, or simply by a discrete value.

Evaluation of the heat flux effects on humans is a complex issue. Therefore, simplification of the reality for the purposes of RAE can lead to certain simplifications in the process of modeling the effects on humans. Some of the models employed therefore take into account only the heat flux critical value without regard to the exposure time, or with regard to only predetermined exposure time. Other models, such as the models based on probit functions, apply a far more comprehensive approach based on the dose-effect relationship.

In the introductory section of this contribution, basic types of fires that may occur in plants storing dangerous flammable substances will be mentioned. Subsequently, a short description of radiative heat transfer principles will be given for better understanding of the nature of the heat flux phenomenon. Next follows a theoretical analysis of the factors influencing the effects of thermal radiation exposure on human lives and health. In the final section, models that can be applied in RAE to determine the effects will be categorized and their brief description will be given.

\section{Materials and methods}

\section{Types of Industrial Fires}

Industrial fires involving dangerous flammable substances often have very specific characteristics. Physicochemical events resulting from the initiation of flammable substances employed in industry are often different from those known in common fires and they, by their nature, endanger greatly human lives and health. Basic types of fires are presented in Tab. 1 below.

\section{Radiative Heat Transfer}

Although heat transfer can have diverse effects, this contribution focuses solely on thermal radiation. The term "radiation" is used to describe many different phenomena. Among them are visible light or ionizing radiation, such as X-ray and gamma ray radiation.

Thermal radiation is an electromagnetic radiation emitted from the surface of an object occurring due to the object's temperature. Any material that has a temperature greater than absolute zero emits a certain amount of radiative energy. Thermal radiation is generated when heat caused by the movement of charged particles within atoms is transformed into electromagnetic waves. Electromagnetic waves propagate independently of the environment, which means they can travel

VŠB - Technical University of Ostrava, Faculty of Safety Engineering, Ostrava, Czech Republic, jakub.dlabka@vsb.cz

VŠB - Technical University of Ostrava, Faculty of Safety Engineering, Ostrava, Czech Republic, barbora.baudisova@vsb.cz

VŠB - Technical University of Ostrava, Faculty of Safety Engineering, Ostrava, Czech Republic 
through empty space and air. Radiation can also, depending on the characteristics of the material and the radiation energy, penetrate through other materials. In some cases, radiation manifests itself rather in form of particles, but this phenomenon is not relevant for the basic understanding of heat transfer from fire (Hartin, 2010). of a fire depends on the size and shape of the flame surface; the heat formed during combustion; the fraction of radiated heat; the quantities of soot that is produced during combustion and forms the luminous part of the flame; water vapor present; carbon monoxide contained in the air; and the position of the object (Casal, 2008).

Tab. 1 Summary of types of fire events in industry involving dangerous substances

\begin{tabular}{|c|c|c|c|c|}
\hline & $\begin{array}{c}\text { Heat flux level } \\
\quad\left[\mathrm{kW} \cdot \mathrm{m}^{-2}\right] \\
\text { (O'Sullivan 2004) }\end{array}$ & $\begin{array}{c}\text { Anticipated } \\
\text { duration of } \\
\text { exposure to heat } \\
\text { flux }\end{array}$ & $\begin{array}{c}\text { Other adverse } \\
\text { effects }\end{array}$ & Subsequences \\
\hline Pool Fire & $50-150$ & Minutes to hours & $\begin{array}{l}\text { Combustion } \\
\text { products, } \\
\text { convective heat } \\
\text { transfer }\end{array}$ & $\begin{array}{l}\text { Frequent initiation by a flash } \\
\text { fire or a vapor cloud explosion. } \\
\text { A boilover and a fireball may } \\
\text { eventually occur. }\end{array}$ \\
\hline Jet Fire & $100-250$ & Minutes to hours & $\begin{array}{l}\text { Convective heat } \\
\text { transfer }\end{array}$ & May precede BLEVE. \\
\hline Fireball & 270 & Seconds & $\begin{array}{l}\text { Overpressure, } \\
\text { dispersion of } \\
\text { flashing liquid }\end{array}$ & $\begin{array}{l}\text { Occurs during boilover or } \\
\text { BLEVE. }\end{array}$ \\
\hline Flash Fire & 170 & Seconds & $\begin{array}{l}\text { Overpressure, } \\
\text { unbreathable } \\
\text { atmosphere }\end{array}$ & $\begin{array}{l}\text { May proceed at various rates, often } \\
\text { up to the rate of detonation, in a } \\
\text { confined environment manifested } \\
\text { rather as a vapor cloud explosion. } \\
\text { May lead to a pool fire. }\end{array}$ \\
\hline
\end{tabular}

Thermal radiation combines with a wide range of frequencies, as shown in Fig. 1. The electromagnetic spectrum includes radiation in broad range of wavelengths; a large portion of the electromagnetic spectrum cannot be observed by the human eye. In the study of fire behavior, the infrared portion of the spectrum is of crucial importance. The energy emitted at each wavelength is dependent on temperature. Frequency and energy of emitted radiation increase as temperature increases. This is reflected by the color changes from red to yellow and then to white, depending on how much the object is heated. If the color change is visible, most of the radiative energy is in the infrared spectrum.

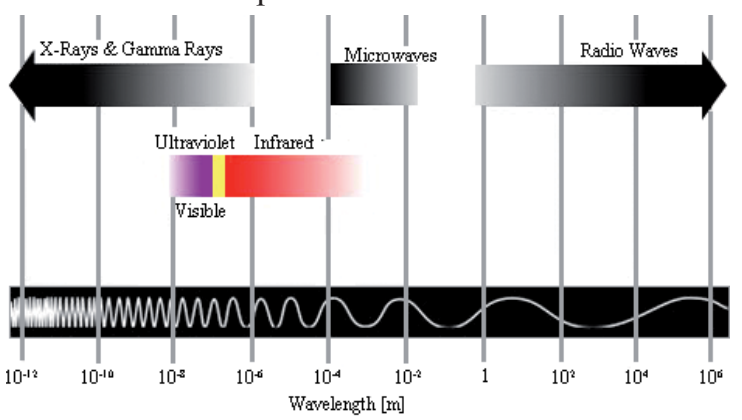

Fig. 1 Electromagnetic spectrum (Hartin, 2010)

Electromagnetic waves of any frequency heat objects' surfaces and are absorbed by them. The amount of heat emitted onto objects in the vicinity
It is important to specify the nature of heat flux, which is defined as the rate of heat transfer per unit cross-sectional area. In Czech, the term "tepelný tok" (tepelný = heat, tok = flux) is defined as the rate of heat transfer per cross-sectional area, whereas rate of heat transfer per unit cross-sectional area (heat flux) is referred to as "hustota tepelného toku" (hustota $=$ density), thus the term "density of heat flux" in verbatim translation. In risk analysis the term "tepelný tok" is often used instead of "hustota tepelného toku". The reason is the adoption of data from English written literature, when the English terms "heat flux" or "thermal flux" are translated as "tepelný tok". Linguistically, the two terms match but from a physical point of view, the correct term for "heat flux" is "hustota tepelného toku". In risk analysis, such a designation will probably continue to be used for its simplicity.

Various models are used to calculate heat flux at certain distance from a fire. Although several models (such as Solid Flame Model, Field Model, Point Source Model) exist, in this contribution we describe only the simplest way to determine heat flux at a given distance from fire source. For its simplicity, the Point Source Model was chosen. (Hartin, 2010). 


\section{Point Source Model}

The point source model is the simplest model to determine the heat flux intensity. This model considers fire and flame surface as a point source located in the geometric center of the flames. Radiated energy is then considered as a ratio of the total energy produced from a fire. It is assumed that energy is radiated in all directions (Hartin, 2010).

For point sources, the radiation intensity varies reciprocally with the square of the distance from source, which is illustrated in Fig. 2. Doubling the distance reduces the radiation intensity four times, that is to $1 / 4$ of its original value.

When radiation is emitted from other than a point source, as it is under fire conditions, dependence of the decrease in radiation intensity is more complex. If the area of the source is large compared to the distance, heat flux decrease does not correspond to the reciprocal of the square of the distance. There is a simple rule: if the distance from source is greater than 5 times the dimensions of the source, the reciprocal square of the distance can be used to calculate the heat flux (Hartin, 2010).

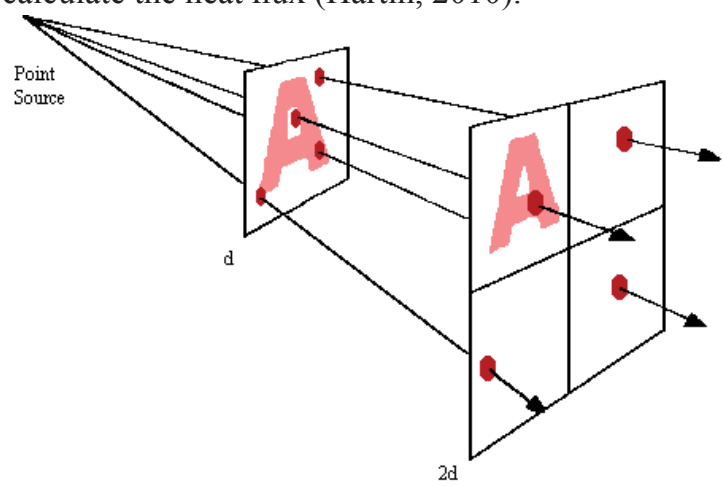

Fig. 2 Heat flux decrease with distance (Hartin, 2010)

Another parameter influencing the heat flux intensity at a certain distance from source is the absorption of thermal radiation by atmosphere and the position of the surface hit by thermal radiation. Particles of water and carbon dioxide in the atmosphere can partially absorb heat transferred by thermal radiation. The thermal radiation intensity may therefore vary depending on the distance from source and on the amount of absorbed heat. The amount of carbon dioxide contained in the atmosphere is basically constant, but the number of molecules of water can vary depending on the temperature and humidity (Casal, 2008).

The physicochemical nature of the heat flux is common to all industrial fires and for the purposes of RAE it is necessary to know the effects of this phenomenon on humans, particularly from a biological point of view.

\section{Results}

\section{Effects of Thermal Radiation on Humans}

In this contribution, we focus solely on the effects of thermal radiation, therefore other factors, such as effects caused by combustion products, thermal convection or others, are not taken into consideration. The response of an organism to the energy transfer is affected by many factors, such as conductivity of tissues, peripheral blood perfusion affecting the degree of absorption or dissipation of heat in tissues, pigmentation, hairiness, thickness of the keratin layer of skin (stratum corneum) or water content in the tissues of the affected area. The surface temperature of the skin can also vary within the extreme limits of human exposure to an energy source (Pokorný, 2004).

The main effect of heat flux in humans is the skin burn. The severity of burns depends on heat flux intensity $\left(\mathrm{kW} \cdot \mathrm{m}^{-2}\right)$ and received dose. Burns are basically classified into three categories:

- First degree burns. They manifest with erythema and pain.

- Second degree burns. They are deeper wounds $(0.1 \mathrm{~mm})$; the skin reddens and blisters form.

- Third degree burns. They are deep injuries (1 $2 \mathrm{~mm}$ ); the victims lose sensitivity in the affected area; the skin is damaged and destroyed to its full depth and its color is yellow or black.

The probability of death can be determined only for the second and third degree burns. In these burn degrees, the skin layers protecting the body against external influences are severely damaged or destroyed on a large body surface area. As a result, water loss in the human body occurs and the probability of infection or death increases. The probability of survival in such a situation can be expressed as a function of the percentage of body area affected and the age of victim. Moreover, if a large portion of the body surface is affected, the victim may fall into a state of shock (Casal, 2008).

Burn mortality is influenced by a large number of factors that include age, inhalation injuries, existing medical complications, medical complications resulting from burns, quantity and type of clothing, rapidness and methods of health care, and the body part that has been burned. Age is one of important factors determining severity of thermal trauma. Apart from the early prognosis, it influences the long-term/lifetime prognosis. It has been repeatedly 
demonstrated that individuals younger than two and older than sixty years of age have a higher burn mortality rate than other age groups (Pokorný, 2004).

An important factor in determining the potential mortality rate is the burn wound depth. It corresponds not only to the intensity of heat flux, but also to its duration. For example, temperatures of even several thousand degrees Celsius applied for a fraction of a second produce superficial scorches whereas temperature of 43 degrees Celsius applied for more than 60 minutes destroys skin to its full depth (Pokorný, 2004).

If we focus on accidents caused by fires, we encounter not only physical, but also psychic damages. Many victims may die not due to the extent and severity of their somatic injuries, but as a result of severe psychological stress and mental breakdown. The victims are prone to "blind action", when they are blinded and respond to stimuli in a confused manner, and to chaotic behavior. They usually do not realize that their life is in danger. This condition is referred to as "trauma agnosis" and it was, for example, the cause of death of many Hiroshima thermally injured victims (Pokorný, 2004).

When evaluating the effects of thermal radiation on humans, clothing is also an important factor to consider. Clothing provides certain protection against burns, but only until it catches fire. The overall trauma of an individual depends on the body surface covered by clothing and his capability to protect himself from thermal radiation. However, it is important to realize that when ignited, the burning clothing causes more severe damage than the one that would have been caused by the action of heat flux itself. The Dutch approach (TNO, 1999) defines the threshold for the ignition of clothing. For the heat flux intensity exceeding this threshold, $100 \%$ probability of death of the exposed individuals is assumed.

When considering the protective properties of clothing, regard must be taken of whether the clothing undergoes spontaneous or piloted ignition. Piloted ignition is considered when clothing ignites due to direct contact with a flame. If piloted ignition is involved, we can assume that after removal of the flame the burning clothes can be ripped off and the danger eliminated. If the clothing ignites spontaneously, i.e. as a result of thermal radiation, it cannot be assumed that the danger will be eliminated after the removal of clothing, because the person will be still exposed to the source of radiation (Mannan, 2005).
Another factor that needs to be considered is the behavior of the affected individuals. In Mannan (2005), it is quoted that it takes 5 sec. until a person is able to respond adequately. After this period of time the person will most likely turn his back to the source of thermal radiation and will seek to escape or hide. Some models consider this behavior too. Known cases show that some of the victims have burns both on the front and the back side of the body. At the moment the event occurred, the victim was facing the event and after initiation turned his back in an attempt to escape.

For the purposes of RAE elaboration, it is necessary to consider all residents, including those who are found in buildings. Buildings are supposed to provide comprehensive protection against thermal radiation effects. However, just as with clothing, it is assumed that they provide protection only until they catch fire. The Dutch approach (TNO, 1999) uses for building ignition (and thus for the increase in the probability of death to $100 \%$ ) the same heat flux level as for the ignition of clothing.

In this chapter, the heat flux effects on humans and principal factors influencing characteristics and degree of these effects have been described. Basic types of industrial fires involving dangerous flammable substances, physicochemical nature of thermal radiation, and its effects on human health have been explained. Now, the basic types of models determining the effects of fires in industry are to be specified.

\section{Models for Determining the Effects of Fires in Industry}

For elaboration of the RAE document, several approaches to determine the impact on the population can be opted for. Functions and discrete values published in internationally recognized methodologies and scientific publications concerning MAP risk analysis process are the bases for the application of various approaches: Purple Book (TNO, 1999); Lees' Loss Prevention in the Process Industries (Mannan 2005); ARAMIS methodology (Casal et al., 2001); CPQRA (AIChE, 2003); Risk Manual Bevi (RIVM, 2009).

In conducting risk analysis, it is usually possible to calculate only heat flux at a given location or, as the case may be, duration of its effects. Unfortunately, other important information such as the age of the affected people or the percentage of body affected by burns, cannot be foreseen in risk assessment in industrial plants. The models used must take into account the limited possibilities for determining the impacts. 
According to the principles of impact evaluation, the models and the approaches to determine the effects of heat flux caused by fire can be divided into following categories:

- Models based on heat flux threshold level,

- Models based on thermal dose,

- Probit functions and other probability models,

- Models based on the percentage body burn.

\section{Models Based on Heat Flux Threshold Level}

To calculate the range of impact or safe distance from a facility where a fire may occur, the heat flux value alone can be used, with a unit of $\mathrm{kW} \cdot \mathrm{m}^{-2}$ (or W.m ${ }^{-2}$ ). These values can be derived from experimental data, real cases, or deduced from other models. Many heat flux values related to various factors have been published and applied worldwide. The biggest drawback of this approach is the limited ability to include exposure time in the calculation. Within the approaches, the values of heat flux related to a specific exposure time are quoted in some cases, but if the values cannot be extrapolated, their application is very limited.

However, during industrial accidents, individuals are exposed to heat flux only for a certain period of time. It can be assumed that this period will be short. In the event of a flash fire or a fireball, the exposure time is limited by the duration of the event itself, amounting to seconds. For pool fire or jet fire, it can be assumed that in case of exposure to heat flux the affected individuals will seek a hiding place or will be able to escape. High level heat fluxes may cause death within a short period of time. In general, it can be stated that the exposure of a person to heat flux continuing for, for example, several minutes is hardly imaginable in industrial accidents.

The method of setting limits based on heat flux threshold values is chosen in the U.S. EPA ALOHA 5.4.1.2 modeling program. It uses heat flux values causing specific effects within one minute (see Tab. 2).

Tab. 2 Heat flux values used in ALOHA 5.4.1.2 program (NOAA, 2007)

\begin{tabular}{|c|c|}
\hline $\begin{array}{c}\text { Heat flux value } \\
{\left[\mathbf{k W} \cdot \mathbf{m}^{-2}\right]}\end{array}$ & Effect \\
\hline 10 & Potential of death within 60 seconds \\
\hline 5 & $\begin{array}{c}\text { Second-degree burns within } 60 \\
\text { seconds }\end{array}$ \\
\hline 2 & Pain within 60 seconds \\
\hline
\end{tabular}

\section{Models Based on Thermal Dose}

The dependence of severity of thermal radiation effects upon the relationship between the heat flux intensity and the exposure time can be expressed in various manners. The simplest way is to introduce a factor determining the severity of damage; in this case, it is the thermal dose, which is the result of a heat flux of a certain value lasting for a specific period of time. Furthermore, it was found out that the impact of high thermal radiation values is more significant than the influence of exposure time; therefore, an empirical expression of this relationship was introduced as:

$$
t \cdot I^{n}=c
$$

where:

$$
\begin{array}{ll}
t & \text { exposure time }[\mathrm{s}], \\
I & \text { heat flux }\left[\mathrm{W} \cdot \mathrm{m}^{-2}\right], \\
n & \text { parameter, } \\
c & \text { constant. }
\end{array}
$$

Eisenberg et al. (1975) introduces in this equation the parameter $n=4 / 3=1.33$, based on data correlation from burn cases. For non-lethal effect he introduces the parameter $n=1.15$. Hymes (1996), however, proposes the same value of the exponent $n=4 / 3$ for both lethal and non-lethal effects. Daydcock (2000) states that the value of $4 / 3$ is based on relatively old data, and does not relate to the infrared radiation. It is, however, considered acceptable and currently the best available. He also mentions the value of 1.15 stating that if more accurate data are available in the future, it may be used in calculating non-lethal thresholds. So the thermal dose value and its unit have been established:

(Thermal Dose Unit) - TDU $=1\left(\mathrm{~kW} \cdot \mathrm{m}^{-2}\right)^{4 / 3} \cdot \mathrm{s}$

The principle of determining the impacts of fire using the thermal dose is used mainly for the purposes of evaluating fire risks on offshore platforms in Great Britain (Daydcock, 2000; HSE, 2006). As an example, the proposed limits are listed in Tab. 3. This approach is convenient mainly because it counts with exposure time.

Tab. 3 Proposed thermal dose limits for offshore workers (Daydcock, 2000)

\begin{tabular}{|c|c|}
\hline Thermal dose $\left[\left(\mathbf{k W} \cdot \mathbf{m}^{-2}\right)^{\mathbf{4} 3 \cdot} \cdot \mathbf{s}\right]$ & Effect \\
\hline 1000 & $1 \%$ lethality \\
\hline 2000 & $50 \%$ lethality \\
\hline 3200 & $100 \%$ lethality \\
\hline
\end{tabular}




\section{Probit Functions and Other Probability Models}

Probit functions determine the dose - effect relationship by mathematical and statistical methods. For exposure evaluation, the dose - effect relationship is taken as a relation of the impact degree of a given inducement, the exposure time, and the effect. It does not count with the form, nor with the degree of the effect. The term "effect" is defined here as an estimation of population that manifests determined response to the impact. Probit functions are most commonly defined for lethality, but functions for other types of effects (first or second degree burns) are also established. Probit functions show how the increase in concentration or in exposure time affects the overall effect. The probit function for heat flux effects is given by:

$$
\operatorname{Pr}=a+b \cdot \ln \left(I^{\frac{4}{3}} \cdot t\right)
$$

where:

$a, b$ regression constants (see Tab. 4),

$t$ exposure time [s],

I heat flux $\left[\mathrm{W} \cdot \mathrm{m}^{-2}\right]$ or $\left[\mathrm{kW} \cdot \mathrm{m}^{-2}\right]$.

In risk analysis, the probit function is most often used for the evaluation of toxic effects, because the data obtained from toxicological tests on animals can be extrapolated. For thermal radiation effects, adequate experiments on animals cannot be performed (except for some cases), since the character of human and animal skin differ substantially. If experiments are performed, they are conducted to observe response of the animal (e.g. pig) skin as such. It is not possible to perform experiments in which a certain number of individuals is exposed to heat flux, as it is common in inhalation toxicology tests, to obtain data on mortality rate for extrapolation to probits. It is therefore possible only to draw on limited data obtained from historical experience.

Eisenberg et al. (1975) uses results published in White (1971), where the effects on humans exposed to ultraviolet radiation in nuclear attacks in Nagasaki and Hiroshima are discussed in detail. This model is still widely used because it is, for obvious reasons, impossible to conduct further experiments on humans or animals. Experimental data, however, show that models based on ultraviolet radiation may overestimate the thermal dose obtained from a source emitting infrared light up to twofold. The original model has been modified several times by various authors (see Tab. 4).

Models using the probit function make possible to determine the percentage response of affected individuals for any value of heat flux and exposure time. Its disadvantage is how it is established as it is based on data that are considered obsolete and only limitedly verifiable.

\section{Models Based on the Percentage Body Burn}

Models based on the percentage body burn can be based somewhat better on empirically derived data. Mortality of individuals in relation to the percentage of body burn can easily be determined from the cases of burned people treated in hospitals. Many studies investigate survival rate from actual cases and establish models for calculating mortality depending on age and percentage body burn. The key issue in this case is to determine the surface area of

Tab. 4 Probit functions for heat flux ( $\mathrm{a}$ and $\mathrm{b}$ are regression constants used in equation 2 )

\begin{tabular}{|c|c|c|c|c|c|c|}
\hline Effect & $\mathbf{a}\left[\mathbf{W} \cdot \mathbf{m}^{-3}\right]$ & $\mathrm{a}\left[\mathrm{kW} \cdot \mathrm{m}^{-3}\right]$ & b & Author & Note & Key publications \\
\hline Lethality & $-38,48$ & $-14,9$ & 2,56 & $\begin{array}{l}\text { Eisenberg, } \\
\text { Lynch, } \\
\text { Breeding }\end{array}$ & Based on nuclear explosion data & $\begin{array}{l}\text { Mannan, } 2005 \\
\text { VROM, } 2005 \\
\text { AlChE, } 2003\end{array}$ \\
\hline Lethality & $-36,38$ & $-12,8$ & 2,56 & Tsao a Perry & $\begin{array}{l}\text { Modified Eisenberg model (includes } \\
\text { infrared radiation) }\end{array}$ & $\begin{array}{c}\text { TNO, } 1999 \\
\text { Mannan, } 2005 \\
\text { VROM, } 2005 \\
\text { RIVM, } 2009 \\
\end{array}$ \\
\hline Lethality & $-37,23$ & $-13,65$ & 2,56 & $\mathrm{TNO}$ & $\begin{array}{l}\text { Modified Eisenberg model (for } \\
\text { individuals protected by clothing) }\end{array}$ & $\begin{array}{c}\text { Mannan, } 2005 \\
\text { Casal et al., } 2004\end{array}$ \\
\hline Lethality & $-29,02$ & $-10,69$ & 1,99 & Lees & $\begin{array}{c}\text { Based on pig skin experiments and } \\
\text { Eisenberg model }\end{array}$ & $\begin{array}{l}\text { Mannan, } 2005 \\
\text { VROM, } 2005\end{array}$ \\
\hline $\begin{array}{l}1^{\text {st }} \text { Degree } \\
\text { Burns }\end{array}$ & $-39,83$ & $-12,03$ & 3,018 & TNO & Developed by TNO & $\begin{array}{l}\text { Mannan, } 2005 \\
\text { VROM, } 2005\end{array}$ \\
\hline $\begin{array}{l}2^{\text {nd }} \text { Degree } \\
\text { Burns }\end{array}$ & $-43,14$ & $-15,34$ & 3,018 & TNO & Developed by TNO & $\begin{array}{l}\text { Mannan, } 2005 \\
\text { VROM, } 2005\end{array}$ \\
\hline
\end{tabular}


the body exposed to heat flux if a person is exposed to a fire. Estimation of the percentage of affected body surface depending on clothing is one of the approaches. VROM (2005) assumes that in a clothed adult the bare skin makes $20 \%$ of the body surface, while in a child it is $30 \%$. In such cases, protective properties of clothing are to be also included.

These models are convenient because empirical data can be used for their establishment. However, their applicability for AER is limited because the percentage of affected body surface cannot be assumed from the mere heat flux value. Still, they may serve as a basis for determining other models established on the basis of heat flux as such.

\section{Conclusion}

In prevention of major accidents, different types of fires with transfer of danger through thermal radiation are considered. Thermal radiation is dangerous because the transfer is practically instantaneous (the speed of light). To assess the effects of emergency events in which the danger is transferred by thermal radiation, many factors must be taken into account - from the characteristics of individuals (age, amount of clothing) to external factors (transmissivity of atmosphere). Only few of these factors can be taken into account in the process of elaborating RAE.

In RAE elaboration and in determination of threshold effects it is necessary to use some of the published models. The simplest ones are based only on a specific discrete value of heat flux which is considered to cause a given effect. This approach can be regarded as satisfactory as it can be assumed that the exposure of an individual to heat flux will last for a short time only. A more accurate approach uses thermal dose, value of which includes effects of the impact lasting for a certain period of time. Even more comprehensive approach is represented by probit function that reflects the dose - effect relationship and determines the corresponding degree of the impact, usually lethality. The drawback of probit functions that are used to determine the effects of heat flux, is that most of the world's published documents are based on modifications of the model published by Eisenberg et al. (1975). This model is based on data obtained from nuclear attacks on Hiroshima and Nagasaki, and today many experts consider it outdated and inaccurate.

However, due to the absence of more recent data and impossibility to perform another tests, at the current state of knowledge, it is (in modified versions) accepted as sufficient. Another option is the application of models depicting the relationship between lethality and affected body surface area, which can be based on empirical data obtained from medical practice. However, this approach is very difficult to apply in conditions of MAP as the percentage of the body affected is difficult to estimate in risk analysis in enterprises with dangerous substances.

\section{Acknowledgements}

This contribution is supported by SGS 023/2101/ SV0231121 project; "Support for Science and Research in Moravian-Silesian Region - subsidy title No. 5" project, contract number 01737/2010/ RRC; and Security Research Programme in the Czech Republic for 2010 - 2015 within the VG20112013069 project.

\section{References}

CASAl, J., PlANAS, E., DELVOSALlE, C., FIÉVEZ, C., PIPART, A., LEBECKI, K., ROSMUS, P., VALLEE, A. (2004). Accidental risk assessment methodology for industriesin the context of the Seveso II directive, The risk severity index. EVG1 - CT - 2001 - 00036.

CASAL, J. (2008). Evaluation of the Effects and Consequences of Major Accidents in Industrial Plants. Industrial Safety Series, Elsevier, 2008, Volume 8, Pages 61-117. ISSN 0921-9110, ISBN 9780444530813.

EISENBERG, N.A., LYNCH, C.J., BREEDING, R.J. (1975). Vulnerability Model: A Simulation System for Assessing Damage Resulting from marine Spills (VM1). US Coast Guard, AD/A-015 245, NTIS rapport no. CG-D-137-75, 1975.

CPQRA (2003). Guidelines for Chemical Process Quantitative Risk Analysis. USA: Center for Chemical Process Safety/AIChE, 2003. ISBN 0-8169-0720-X. 800p.

TNO (1999). Guidelines for Quantitative Risk Assessment “Purple Book” CPR 18E. $1^{\text {st }}$ Edition. Hague, Netherlands: Committee for the Prevention of Disasters, 1999. 237 p.

HARTIN, E. (2010). Everyday Concepts-Part 4: Radiation [online]. CFBT-US, 2010 [cit. 2011-04-14]. Available at: http://cfbt-us.com/wordpress/?paged $=3$ 
VROM (2005). Hazardous Substances Publication series 1. Methods for determining possible damage ('Green book'). Ministry of VROM [Housing, Spatial Planning and the Environment], 2005.

Health and safety executive. Methods of Approximation and Determination of Human Vulnerability for Offshore Major Accident Hazard Assessment. Health and Safety Executive, January 2006. SPC/Tech/OSD/30.

HYMES, I, BOYDELL, W., PRESCOTT, B. (1996). Major Hazards Monograph: Thermal Radiation: Physiological and Pathological Effects, IChemE, Rugby, UK.

DAYDCOCK, J.H., REW, P.J. (2000). Thermal radiation criteria for vulnerable populations. Report by WS Atkins Consultants \# 285/2000 to Health and Safety Executive, England, 2000.

MANNAN, S. (2005). Lee's Loss Prevention in the Process Industries. $3^{\text {rd }}$ Edition. Oxford: Elsevier ButterworthHeinemann, 2005.

NOAA (2007). Thermal Levels of Concern [online]. Office of Response and Restoration, 2007 [cit. 2011-06-13]. Available at: http://response.restoration.noaa.gov/

O’SULLIVAN, S., HAGGER, S. (2004). Science and exposure Group. Human vulnerability to thermal radiation offshore. 2004, HSL/2004/04.

POKORNÝ, J. (2004). Urgentní medicína. 1. vyd. Praha: Galén, 2004. 547 s. ISBN 8072622595.

RIVM (2009). Reference Manual Bevi Risk Assessments version 3.2. Netherlands: National Institute of Public Health and the Environment (RIVM), Centre for External Safety, 2009. 189 p.

WHITE, C.S. (1971). The nature of problems involved in estimating the immediate casualties from nuclear explosions. Civil effects study. US Atomic Energy Commission, 1971. 